\title{
The interaction of text and visual in specialized dictionary definitions
}

\author{
Bassey E. Antia and Njuasi Ivo
}

"and what is the use of a book," thought Alice, "without pictures...?" - Lewis Carroll, Alice in Wonderland

\begin{abstract}
Although visuals have been co-deployed with text in specialized dictionaries as far back as the European Renaissance, the interaction of both representational modalities is relatively under-researched. As a consequence, available knowledge is relatively limited with respect to the kinds of visuals employed in specialized dictionaries, the kinds of definiendum that elicit specific types of visuals, the functions of visuals relative to text in definitions, and the association between particular visuals and visual-text functions. This study sheds light on these questions from the perspective of specialized dictionaries in two fields (Biology and Mechanical Engineering). Significantly, the study underscores how the ontology or nature of Biology and Mechanical Engineering appear to determine both the selections made of visual types and the dominant text-visual relationships. The study further makes a contribution to cleaning up the Augean clutter that is the terminology of visuals.
\end{abstract}

\section{Introduction}

In environments where Western writing systems are used, it is not uncommon to refer to many non-verbal signs as visuals. These visuals range from drawings and photographs through mathematical equations and chemical formulas to tables and charts. From Chomsky's (1968) Language and Mind to Kress and Van Leeuwen's (1996) Reading Images, the status of symbolization as a whole (including visuals) in linguistic theorization has undergone fundamental change. Chomsky described the capacity for symbolic reference as uniquely human (in contrast to the more iconic, prelinguistic symbolization of non-human communication), and this has had perhaps the unintended consequence of engendering a neglect, if not a deprecation, of non-verbal signs in theorization about language and communication.On the other hand, Kress and Van Leeuwen (1996) accord independent semiotic or meaning-making status to non-linguistic symbolization (e.g. images, color, space) in human communication, and show it as having the same ideational, interpersonal and textual functions ascribed to language narrowly defined. 
In between what would sometimes seem to be two extremes, there lies a burgeoning literature on the co-deployment in texts of verbal symbols attested in the script of a language, and visuals such as diagrams, photographs, maps, tables, graphs, formulas, and the like. There are a number of directions that can be distilled from this body of work.

One direction establishes the significance of visuals in texts. Lemke (1998) finds in one of several corpora of published scientific writings which he analyzes that there is an average of 16.2 visuals per article (of 14.8 pages average length). With respect to equations specifically, Lemke finds an average of 1.4 equations per page. In an analysis of Finnish newspapers, Järvi (2002) finds that visuals account for between $4 \%$ and $37 \%$ of the total space of these newspapers. In a study of school science textbooks and press articles about science and technology, Dimopoulos et al. (2003) establish the average density of visual illustrations as follows: $\mathbf{1 1 . 1}$ visuals per 1000 words in school science textbooks, and 1.2 visuals per 1000 words in press articles. In a diachronic study of visual representations in research articles in Nutrition Biochemistry, Magnet (2001) finds that for five time periods, viz. 1929-1959, 1960-1969, 1970-1979, 1980-1989 and 1990-1999, the space occupied by visuals in research articles was $27.8 \%, 30.2 \%, 26.3 \%, 30.1 \%$, and $25.5 \%$ respectively.

Another thrust in the literature is the identification and classification of visual types. Thus, Galinski and Picht (1997) group visuals into two major categories: (1) alphanumeric symbols (e.g. "A1" in school grading systems) and (2) pictorial representations (photographs, tables, graphs, charts - flow, pie, bar, and so on). ISO 704 (2009) identifies the following types of visual or graphic representations: abstract illustrations, network diagrams, matrix diagrams, schematic diagrams, iconic illustrations, drawings, etchings, photographs, statistical diagrams, line charts, bar charts, pie charts, and mixed figures which combine two or more forms. Darian (2001), following Doblin (1980), classifies visuals into idiographic (marks such as road signs, flags, symbols, and equations), diagrammatic (tables, charts, graphs, diagrams, and maps), and isogrammatic (drawings, photographs, videos, animations and models). Dimopoulos et al. (2003) identify three categories: realistic (visual images that represent reality according to human optical perception such as drawings, photographs, videos and animations), conventional (visual images that represent reality in a codified way such as graphs, maps, flow charts, molecular structures and diagrams), and hybrid (visual images that include elements from the above two classes: realistic and conventional).

A third direction in the literature documents the functions of visuals. In Järvi's (2002) analysis of newspapers, visuals aid spatial economy, simplify complex knowledge, make comparisons possible and lend credibility. In Darian's (2001) study of Biology and Chemistry textbooks, visuals are identified with the following functions: interestmotivation, understanding, remembering, elaboration, economy, summarizing, argument-persuasion, reasoning, analysis, exploration, discovery and problem-solving. In their study of school science textbooks and press articles on science and technology, Dimopoulos et al. (2003) identify the following functions: narrative (representing the stages in changing processes), classificational (showing the types of relationships between the concepts presented in terms of superordinate-subordinate entities), analytical (showing meronymic or part-whole relationships) and metaphorical (images symbolizing 
meanings and values beyond what they literally represent, for instance using the image of Celsius to demonstrate a thermometer). Kendler (2005) presents a four-fold categorization of the relationship of visual to text: (1) redundant (both visual and text have identical content), (2) complementary (different contents or perspectives are conveyed by each mode but both modes have equal importance in making the message understandable), (3) supplementary (one mode serves to elaborate, reinforce or instantiate the idea conveyed in the dominant mode), and (4) stage-setting (text and visual have different content but one of the modes is used to prime readers to the content presented in the other mode. Marsh and White (2003) identify: (a) visuals with functions expressing little or no relationship to the text, (b) visuals with functions expressing a close relationship to the text, and (c) visuals with functions going beyond the text.

Now, although the fortunes of visuals have changed significantly for the better in linguistic scholarship, the basis of much of this scholarship has been generally provided by genres associated with, for instance, scientific writing, newspapers and children's books. Unfortunately, the co-deployment of text and visuals has not been as extensively studied in dictionaries. Yet, a cursory look at dictionaries, both general and specialized, shows that they, too, contain visual representations. They have, at least as far back as the (European) Renaissance, with Valturius' 1472 dictionary on warfare: Vocabula militaris ac publici honoris prisca atque preclara (Hupka 1999). Regrettably, the status of these visuals as integral components of dictionary definitions is sometimes unnoticed, as when ISO 1087-1 (2000) defines a definition as "the representation of a concept by $a$ descriptive statement which serves to differentiate it from related concepts" (our emphasis). This misses the point that, in some fields, visuals may in fact carry much of the burden of defining (Laurén et al. 1998, 207f).

There are some exceptions to this relative neglect, and they have the merit of underscoring the significance of and opportunities for researching the interaction of text and visual in dictionaries. Some of these exceptions include Faber et al. (2007) who study the link between verbal and visual representations of specialized concepts in a coastal engineering web-based database, and Blachowicz et al. (2005) who examine the use of images and semantic webs (synonymy, antonymy) together with the verbal modality to enhance the learning of vocabulary among school children. Antia (2002), building on Lemke (1998), suggests that visuals in terminology resources are potentially tri-functional as they may possess a presentational aspect (which shows how an object is construed), an orientational aspect (which directs attention to specific parts of the represented object), and an organizational aspect (that creates a sense of logical coherence between constituent visuals or between visual and text). There is, especially, the wide-ranging work by Hupka (1989a, 1989b, 1999) dealing with, among others: the economics of space as it relates to the placement and size of visuals; the nature of decision-making concerning what definiendum should be illustrated (in comparable dictionaries or from one edition of a dictionary to another); the preference by dictionaries for either drawing or photographs; the relations obtaining among definition and illustration, illustration and legend, legend and definiendum; the cognitive dimensions of the interaction of visual and text; the functional classes of illustrations; and so on. With respect to functional classes, Hupka (1989a) identifies nine categories, including illustrations that focus only on the object designated by the definiendum, illustrations that are a composite of several others 
(and are necessitated by, among others, the absence of a single representative prototype), sequential illustrations (depicting the definiendum in different phases), structural illustrations which are used when the definiendum is best represented as part of a broader entity, functional illustrations that depict the internal structure or the functioning of the definiendum, and terminological illustrations that serve principally to introduce the vocabulary of a field.

Even with the insights provided by these studies, there still are important gaps in our knowledge of visuals in specialized dictionaries. Some of these gaps are captured by the following questions:

1. What types of visuals are used in dictionaries?

2. What types of visuals are used for what kinds of definiendum (that which is defined)?

3. What functions do visuals play in relation to text in dictionary definitions?

4. Are particular forms of visuals associated with given functions?

This article attempts to answer these questions. In subsequent sections, we will present, in turn, an overview of definitions, terminological problems associated with visuals, the methodology for the study, the results, a discussion of the results, and the conclusion.

\section{An overview of definitions}

A basic terminology of definition recognizes at least the following concepts: a definiendum (that which is defined; plural=definienda), a definiens (what is said of the definiendum) and a definitor which is the link or equivalence relation between the definiendum and the definiens (Picht and Draskau 1985; Dahlberg 1995; Eck and Meyer 1997; Barnbrook 2003). Definitions serve a variety of purposes, including fixing a concept (especially during an assignment of term to concept), explaining a concept, and relating one concept to another (Antia 2005). Various types of definition exist. The classical definition comprises a definiendum and a definiens, with the latter comprised of a (closest) superordinate genus and differentiating characteristics (Eck and Meyer 1997); for example: a surgeon is a specialist physician who cuts people open. As Barnbrook (2003) shows, several dictionaries reverse the definiendum - definiens order (e.g. a specialist physician who cuts people open is a surgeon).

A common three-fold typology (Sager 1990; Sager and Ndi-Kimbi 1995; de Bessé 1997) recognizes a terminological definition (similar to the classical definition), a lexicographical definition (which, for instance, explains words: e.g., cranial hemorrhage is bleeding of the skull), and an encyclopaedic definition (which gives extensive, general knowledge). In practice, though, definitions provided in specialized dictionary entries are of a mixed kind. Such definitions may begin with the etymology, a gloss or synonyms of the term (lexicographical definition), then situate the relevant concept in a relevant knowledge structure by relating the definiendum to its genius or a contextualizing superordinate concept (terminological definition), and finally provide information on such other dimensions as functions, types, structural features and so on (encyclopedic definition). 
Although the extensive nature of information in specialized dictionary entries might make one think of dictionary definitions as conventional specialized texts, it has been pointed out (by Leonardi 2010) that dictionaries differ from other texts. In texts, relevant information is distributed over several passages (with the reader having to constructively synthesize). The multidimensionality or the several legitimate perspectives to a concept (Gerzymisch-Arbogast 1996; Bowker 1997) may explain why any two such passages offered as predication of a definiendum may appear very dissimilar (Antia 2000, 200f). Information compactness or density remains a central concern in dictionary entries not only because of the issue of space (at least in hardcopies) but also because users consult dictionaries and texts with rather different mindsets and pragmatic considerations. Visuals, sometimes in the form of knowledge representation formalisms, may present opportunities for achieving spatial and informational economy.

\section{The terminology of visuals: Cleaning an Augean clutter}

In the relevant literature reviewed above, definitions of visual types tend to be neglected. There is a certain "taken-for-grantedness" in respect of how the various types of visuals should be understood. For instance, in Lemke (1998), Järvi (2002), Dimopoulos et al. (2003), Magnet (2001), Galinski and Picht (1997), Darian (2001), Doblin (1980), Kendler (2005), Marsh and White (2003), Faber et al. (2007), Blachowicz et al. (2005), we are not told what constitutes, say, a drawing or a diagram, or what distinguishes one type of visual from another.

For the researcher in this field, looking up dictionaries is only of limited help, especially because the genus (proximum) employed from definition to definition creates a chain of indistinctness. For instance, Webster's Online Dictionary defines a graph as "a diagram (a series of one or more points, lines, line segments, curves, or areas) that represents the variation of a variable in comparison with that of one or more other variables" and a diagram as a "a drawing that shows arrangement and relations (as of parts)". What this says, in other words, is that a graph is a diagram, and a diagram is a drawing! Harper Collins Collins Cobuild Advanced Learner's English Dictionary defines a chart as "a diagram, picture or graph which is intended to make information easier to understand". This definition lengthens the chain of indistinctness in rather curious ways (a chart is a diagram, a chart is a graph). Longman Dictionary of Contemporary English considers bar chart and bar graph as synonymous, thus conflating in this instance chart and graph.

The web-published periodic table of visualization methods by Lengler and Eppler is a rather comprehensive listing of visuals types (see: www.visualliteracy.org/periodic table/periodic table.html?=54\#). Although it does not provide definitions, it provides useful bases for deriving definitions (e.g. entities being represented - such as data versus information; structures versus processes; the kind of thinking supported; the amount of detail provided). Perhaps it is a reflection of the conceptual imprecision in this area that inferred definitions are not infrequently inadequate vis-à-vis real data. For instance, our inferred definition of a "table" is a visualization method for representing structures (rather than processes) that allows for synthesizing information even while offering both detailed and general perspectives. However, in our study, in the entry for "table" in Table 1, what is referred to by the dictionary as a table is not a structure, but a listing of the various blood groups based on 
given variables (antigens A and B on the surface of red blood cells and antibodies against this in blood serum).

Lengler and Eppler's periodic table in particular makes very obvious the "misclassificatory" nature of visual terms (in English at least). Although flowcharts and Gantt charts, for instance, are morphologically sub-types of chart (because they have chart as morphological head), they are onomasiologically (based on the inferred criterion of dynamism) more like diagrams. By the same token, some visuals that have diagrams in their designations (e.g. Venn diagram) may be considered as having an inappropriate morphological head, while some visuals that do not have diagrams in their designations (e.g. process event chains, decision tree) can make a strong case for being considered diagrams.

The task of cleaning up the terminology in this area is quite an extensive one and the current study hopes to make a modest contribution to the effort.

\section{Methodology}

To answer the research questions, data on definitions (in which text and visual are jointly used) were obtained from two specialized dictionaries, namely: Arora's (2007) Academic's Dictionary of Mechanical Engineering (first edition) and Oxford Dictionary of Biology (fourth edition), published in 2000. The former is henceforth abbreviated as $\mathrm{M}$, and the latter as B. M has 5,113 entries, 97 (2\%) of which have visual representations. B contains 4,688 entries, 129 of which (2.8\%) have visual material. Collapsing the figures for both dictionaries, 226 visual-text pairs were examined in this research.

Given the challenges surrounding the definition of visuals types, we inductively (on the basis of our data) came up with working definitions. See Table 1. In each of the two dictionaries, visuals were classified following the form-based classification (idiographic, diagrammatic, isogrammatic) proposed by Darian (2001) as reviewed earlier. The definiendum in each definition to which a visual is attached was then examined at two levels: first, according to whether the concept was static (not moving or changing in relation to space and time, e.g., house) or dynamic (moving or changing in relation to time and space : actions and events, e.g., house search (Pilke 1999; Kalverkämper 1993); secondly, according to whether the definiendum was a concept based on a material object (made of matter and decomposable into its molecular and sub-molecular constituents), or an immaterial object (not made of matter and thus not analyzable in terms of its molecular constituents).

Furthermore, we examined each visual along with the associated text in order to suggest what function the visual has relative to the text. For this purpose, our reporting framework was Marsh and White's (2003) scheme which identifies: (a) visuals with functions expressing little or no relationship to the text, (b) visuals with functions expressing a close relationship to the text, and (c) visuals with functions going beyond the text. Then, finally, to find out whether particular forms of visuals are associated with given functions, we paired the forms of visuals in our data with the three categories of Marsh and White (2003). 
The analysis was done on the basis of the operational definitions set out on Table 1, and the definitions take into account useful dimensions from other sources. Each definition is illustrated by materials from the dictionaries to be studied.

Table 1. Operational definitions of visual types, with illustration

\begin{abstract}
Equation: a mathematical statement that uses any combination of mathematical operations, including addition, subtraction, division or multiplication to evaluate a given value.
\end{abstract}

Table: a form of visualization of data arranged in columns and rows

Diagram: a form of visualization that explains, rather than represents, the shape, layout or working of something.

Note: Unlike a drawing that represents an object according to human optical perception, a diagram bears no physical resemblance to the entity it is associated with.

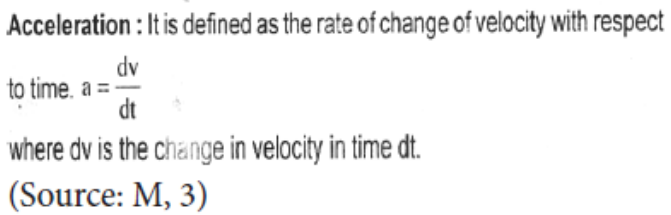

ABO system One of the most important human *blood group systems. The system is based on the presence or absence of *antigens A and B on the surface of red blood cells and *antibodies against these in blood serum. A person whose blood contains either or both these antibodies cannot receive a transfusion of blood containing the corresponding antigens as this would cause the red cells to clump (see agglutination). The table illustratc's the basis of the system: people of blood group $\mathrm{O}$ are described as 'universal

\begin{tabular}{|c|c|c|c|c|}
\hline Group & $\begin{array}{l}\text { Antigens on red } \\
\text { cell surface }\end{array}$ & $\begin{array}{l}\text { Antibodies } \\
\text { in serum }\end{array}$ & $\begin{array}{l}\text { Blood group of } \\
\text { people donor can } \\
\text { receive blood from }\end{array}$ & $\begin{array}{l}\text { Blood group of } \\
\text { people donor can } \\
\text { give blood to }\end{array}$ \\
\hline A & A & anti-B & $A, O$ & $A, A B$ \\
\hline B & B & anti-A & B. 0 & B. AB \\
\hline$A B$ & $A$ and $B$ & none & $A, B, A B, O$ & $A B$ \\
\hline 0 & neither $A$ nor $B$ & $\begin{array}{l}\text { anti-A and } \\
\text { anti-B }\end{array}$ & 0 & $A, B, A B, O$ \\
\hline
\end{tabular}

The ABO blood group system

(Source: B, 1)

beta sheet ( $\beta$-pleated sheet) A form of secondary structure in *proteins in which extended polypeptide chains lie parallel to each other and are linked by hydrogen bonds between the $\mathrm{N}-\mathrm{H}$ and $\mathrm{C}=0$ groups (see illustration). Beta sheets occur in many globular proteins and link polypeptides of the same type in certain fibrous proteins, including fibroin (the protein of silk). Compure alpha helix.

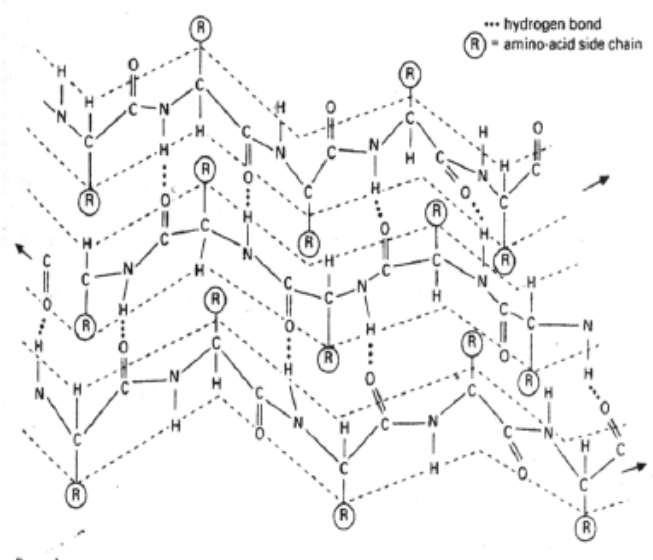

Beta sheet

(Source: B, 65) 
Graph: a form of visualization that shows relationships between two or more amounts usually measured along a horizontal and a vertical axis

Flow chart: a form of visualization that consists of lines connecting shapes to indicate the stages through a process.
Amplitude : The peak (maximum) value of a periodica quantity.

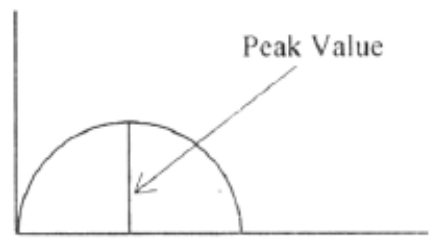

(Source: M, 21)

nitrogen cycle One of the major cycles of chemical elements in the environment (see biogeochemical cycle). Nitrates in the soil are taken up by plant roots and may then pass along "food chains into animals. Decomposing bacteria convert nitrogen-containing compounds (especially ammonia) in plant and animal wastes and dead remains back into nitrates, which are released into the soil and can again be taken up by plants (see' nitrification). Though nitrogen is essential to all forms of life, the huge amount present in the atmosphere is not directly available to most organisms (compare carbon cycle). It can, however, be assimilated by some specialized bacteria (see nitrogen fixation) and is thus made available to other organisms indirectly. Lightning flashes also make some nitrogen

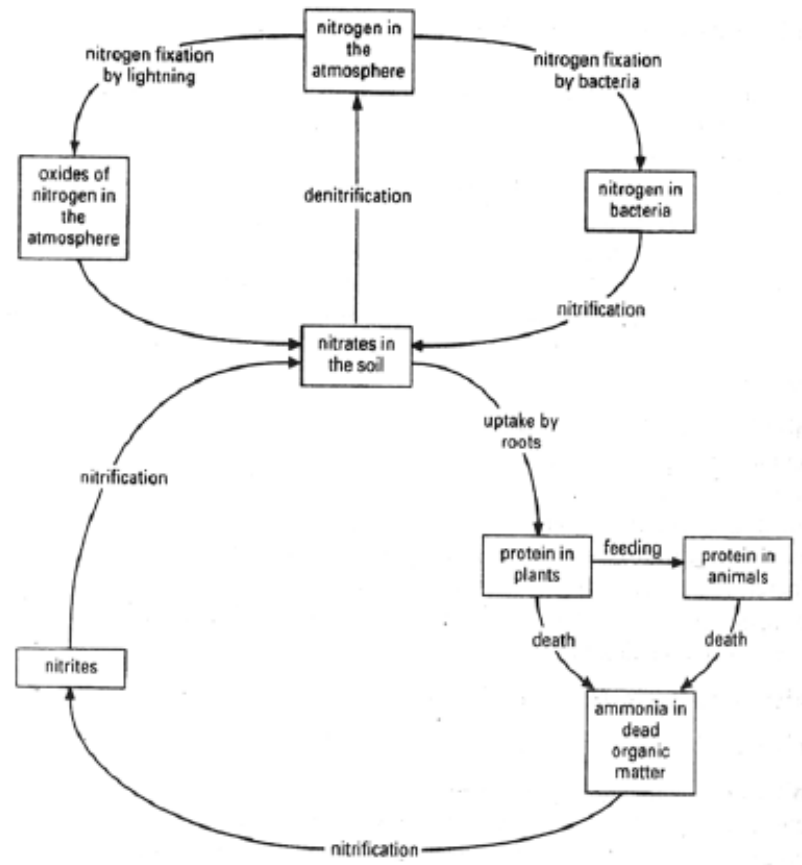

The nitrogen cycle

(Source: B, 408) 
Map: a form of visualization that ical area or part of it. represents a physical or geograph-

continental drift The theory that the earth's continents once formed a single mass and have since moved relative to each other. It was first postulated by A. Snider in 1858 and greatly developed by Alfred Wegener (i880-1930) in 1912. He used evidence, such as the fit of South America into Africa and the distribution of rock types, flora, fauna, and geological structures, to suggest that the present distribution of the continents results from the breaking up of one or two greater land masses. The original land mass was named Pangaea and it was suggested that this broke

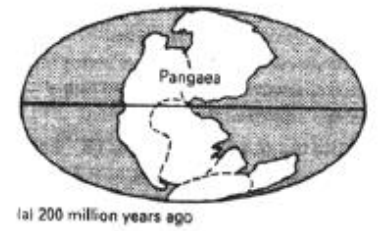

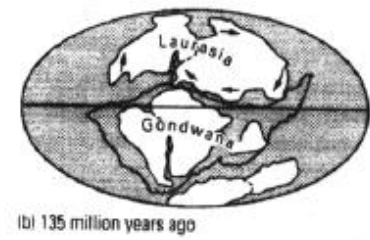

(bi) 135 million vears ago Continental drift

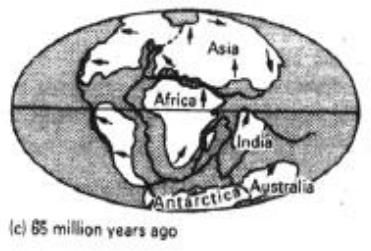

(c) 65 million years ago
(Source: B, 143)

Drawing: a form of visualization made especially with a pencil, pen, marker, or chalk, but not paint, intended to represent an object according to human optical perception. As such, a drawing differs from a diagram in that it bears physical resemblance to the real world entity and therefore does not need special interpretation like a diagram.

Worm wheel : A gear wheel with curved teeth that meshes with a worm

Worm \& Worm Wheel

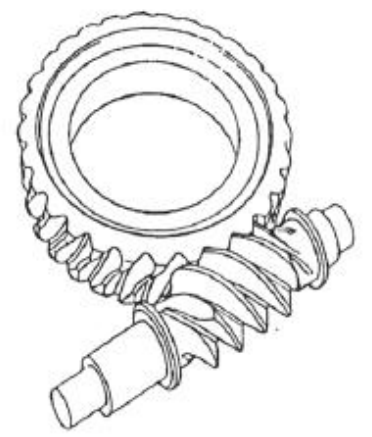

(Source: M, 355)

\section{Results}

To begin with some preliminary and general findings, it might be noted that the ratio of visual to definition is 1:53 in $M$ and 1:36 in B. Expectedly, many of the definitions combine two or more types of definition, even though $\mathrm{M}$ does tend to have a preference for lexicographic definitions (e.g. actinography: a recording actinometer). $\mathrm{B}$, on the other hand, tilts heavily towards encyclopedic definitions, even when definition types are combined. The following example of blood first states a terminological definition (genus: a fluid body tissue, then additional or differentiating characteristics highlighting generic function: acts as transport medium) before going on to provide encyclopedic information:

Blood: A fluid body tissue that acts as a transport medium within an animal. It is contained within a blood vascular system and in vertebrates is circulated by means of contractions of the heart. Oxygen and food are carried to tissues, and carbon dioxide and chemical (nitrogenous) wastes are transported from tissues to excretory organs for disposal (excretion). In addition blood carries hormones and also acts as a defence 
system. Blood consists of a liquid (see blood plasma) containing blood cells (erythrocyte, leucocyte) and platelets (see illustration). Source: B, 78.

Not surprisingly, the average length of a definition is 216 words in B and 39 words in M.

To answer the first research question on the kinds of visuals in the dictionaries, we present a form-based classification of the visuals in our corpus, following Darian's (2001) classification scheme (see Table 2).

Table 2. Forms of visuals in both dictionaries (total for $B=129$; total for $M=97$ )

\begin{tabular}{llllllllllllllll}
\hline Darian's classes & $\begin{array}{l}\text { Idio- } \\
\text { graphic }\end{array}$ & \multicolumn{3}{l}{ Diagrammatic } & & & & & & & \multicolumn{1}{c}{$\begin{array}{l}\text { Isogram- } \\
\text { matic }\end{array}$} \\
\hline Attested instances & Equation Tables & Graphs & $\begin{array}{l}\text { Flow } \\
\text { charts }\end{array}$ & Maps & & Diagrams Drawings \\
\hline Dictionaries & B & M & B & M & B & M & B & M & B & M & B & M & B & M \\
\hline Number of visuals & 0 & 5 & 4 & 0 & 7 & 4 & 9 & 0 & 1 & 0 & 48 & 2 & 60 & 86 \\
Percentage & 0 & 5.2 & 3.1 & 0 & 5.4 & 4.1 & 7 & 0 & 1 & 0 & 37.2 & 2 & 46.5 & 88.7 \\
\hline
\end{tabular}

With respect to the first research question on the kinds of visuals used in the context of dictionary definitions, we notice from Table 2 that although $\mathrm{M}$ employs equations, graphs, diagrams and drawings to define disciplinary concepts, drawings are by far the most frequently used visuals, accounting for as much as $88.7 \%$ of all visual material. With respect to B, it uses drawings almost as frequently as it uses diagrams. Diagrams account for $37.2 \%$ of B's visuals while drawings account for $46.5 \%$. In effect, whereas drawings dominate in $\mathrm{M}$, drawings and diagrams are the dominant visuals in $\mathrm{B}$.

To answer the second research question as to whether certain types of definiendum elicit particular forms of visuals in the dictionaries, we would need data on the nature of these definienda. Table 3 presents the relevant data.

We notice from Table 3 that there are no definienda that are dynamic concepts representing material objects in both the $\mathrm{M}$ and $\mathrm{B}$ data. There are more static concepts representing material objects (81.4\%) in the $\mathrm{M}$ data than in the $\mathrm{B}$ data (63.6\%). In the $\mathrm{M}$ data, the percentage of dynamic concepts representing immaterial objects is lower than the percentage of static concepts representing immaterial (8.2\% as against $10.3 \%)$. Conversely, in the B data, the percentage of dynamic concepts representing immaterial objects is higher than the percentage of static concepts representing immaterial objects (25.5\% as against $9.3 \%)$. 
Table 3. Nature of the definiendum (concept being defined) in dictionary definitions

\begin{tabular}{|c|c|c|c|c|c|}
\hline \multirow[t]{2}{*}{ Dictionary } & \multicolumn{2}{|c|}{$\begin{array}{l}\text { Definiendum as concept rep- } \\
\text { resenting material object }\end{array}$} & \multicolumn{2}{|c|}{$\begin{array}{l}\text { Definiendum as concept rep- } \\
\text { resenting immaterial object }\end{array}$} & \multirow[t]{2}{*}{ Total } \\
\hline & Static & Dynamic & Static & Dynamic & \\
\hline M & $\begin{array}{l}79 \\
\text { (e.g. arbor } \\
\text { press })^{1}\end{array}$ & 0 & $\begin{array}{l}10 \\
(\text { e.g. adden- } \\
\text { dum })^{2}\end{array}$ & $\begin{array}{l}8 \\
(\text { e.g. } \\
\text { Acceleration })^{3}\end{array}$ & 97 \\
\hline B & $\begin{array}{l}83 \\
(\text { e.g. eye })^{4}\end{array}$ & 0 & $\begin{array}{l}12 \\
\text { (e.g. cladis- } \\
\text { tics })^{5}\end{array}$ & $\begin{array}{l}34 \\
\text { (e.g. exponen- } \\
\text { tial growth })^{6}\end{array}$ & 129 \\
\hline
\end{tabular}

With these preliminary results, we now have data (Tables 4 and 5) to answer the second research question on visual types and definiendum type. We will do so by pairing forms of visuals with types of concepts as in Tables 4 and 5 below.

Table 4 reveals that equations tend to be used with both dynamic and static concepts representing immaterial objects. There are only five of such concepts in our data: Acceleration, Cutting speed, Moment of inertia, Reynolds number and Rigidity modulus. From Table 5 we notice that tables can be used to illustrate dynamic as well as static concepts representing both material and immaterial objects. We see further from both Tables 4 and 5 that graphs are used with static as well as with dynamic concepts representing only immaterial objects such as moment of inertia and exponential growth.

Table 4. Pairing of visual form with concept type/definiendum in $\mathrm{M}$

\begin{tabular}{|c|c|c|c|c|c|}
\hline & \multicolumn{2}{|c|}{$\begin{array}{l}\text { Concepts representing } \\
\text { material objects }\end{array}$} & \multicolumn{2}{|c|}{$\begin{array}{l}\text { Concepts representing } \\
\text { immaterial objects }\end{array}$} & \multirow[t]{2}{*}{ TOTAL } \\
\hline & Static & Dynamic & Static & Dynamic & \\
\hline Equations & 0 & 0 & $\begin{array}{l}3 \\
\text { (e.g. moment } \\
\text { of inertia) }\end{array}$ & $\begin{array}{l}2 \text { (e.g. ac- } \\
\text { celeration) }\end{array}$ & 5 \\
\hline Graphs & 0 & 0 & $\begin{array}{l}3 \\
\text { (e.g. ampli- } \\
\text { tude) }\end{array}$ & $\begin{array}{l}1 \text { (e.g. } \\
\text { isothermal } \\
\text { process) }\end{array}$ & 4 \\
\hline Diagrams & 0 & 0 & $\begin{array}{l}2 \\
\text { (e.g. deden- } \\
\text { dum) }\end{array}$ & 0 & 2 \\
\hline Drawings & $\begin{array}{l}78 \text { (e.g. } C \\
\text { clamp) }\end{array}$ & 0 & $\begin{array}{l}2 \\
\text { (e.g. keyway) }\end{array}$ & $\begin{array}{l}6 \text { (e.g. hot } \\
\text { rolling) }\end{array}$ & 86 \\
\hline TOTAL & 78 & 0 & 10 & 9 & 97 \\
\hline
\end{tabular}


Table 5. Pairing of visual form with concept type/definiendum in B

\begin{tabular}{|c|c|c|c|c|c|}
\hline & \multicolumn{2}{|c|}{$\begin{array}{l}\text { Concepts representing } \\
\text { material objects }\end{array}$} & \multicolumn{2}{|c|}{$\begin{array}{l}\text { Concepts representing immaterial } \\
\text { objects }\end{array}$} & \multirow[t]{2}{*}{ TOTAL } \\
\hline & Static & Dynamic & Static & Dynamic & \\
\hline Tables & $\begin{array}{l}1 \\
\text { (e.g. amino } \\
\text { acids) }\end{array}$ & 0 & $\begin{array}{l}2 \\
\text { (e.g. genetic code) }\end{array}$ & $\begin{array}{l}1 \\
\text { (e.g. heterochrony) }\end{array}$ & 4 \\
\hline Graphs & 0 & 0 & 0 & $\begin{array}{l}7 \\
\text { (e.g. exponential } \\
\text { growth) }\end{array}$ & 7 \\
\hline Maps & 0 & 0 & 0 & $\begin{array}{l}1 \\
\text { (e.g. continental } \\
\text { drift) }\end{array}$ & 1 \\
\hline Flowcharts & 0 & 0 & 0 & $\begin{array}{l}9 \\
\text { (e.g. carbon cycle) }\end{array}$ & 9 \\
\hline Diagrams & $\begin{array}{l}30(\mathrm{e} . \mathrm{g} . \mathrm{gib}- \\
\text { berellic acid })\end{array}$ & 0 & $\begin{array}{l}8 \\
\text { (e.g. Cladistics) }\end{array}$ & $\begin{array}{l}10 \\
\text { (e.g. dihybrid cross) }\end{array}$ & 48 \\
\hline Drawings & $\begin{array}{l}52 \text { (e.g. } \\
\text { alimentary } \\
\text { canal) }\end{array}$ & 0 & $\begin{array}{l}1 \\
\text { (e.g. hypermetro- } \\
\text { pia) }\end{array}$ & $\begin{array}{l}7 \\
\text { (e.g. mitosis) }\end{array}$ & 60 \\
\hline TOTAL & 83 & 0 & 11 & 35 & 129 \\
\hline
\end{tabular}

There is only one instance of a map in our data and this illustrates the dynamic concept of continental drift where three maps of the globe are used to show the different stages of the breakaway and gradual drift of the continents over hundreds of billions of years.

Flow charts appear only in our B data on Table 5 and represent only dynamic concepts based on either material or immaterial objects. Both Tables 4 and 5 reveal that diagrams are used with static but not dynamic concepts representing material objects. We will return to this finding in the discussion section in the context of Lengler and Eppler's periodic table of visualization methods. It is, however, noteworthy that for concepts of immaterial objects, diagrams are used with both static and dynamic concepts (examples: dedendum on Table 4 and dihybrid cross on Table 5). Although all the diagrams in our data are used to represent material as well as immaterial objects, it is instructive to note that all these objects are not directly observable to the human eyes. Examples include dedendum and cladistics.

As for drawings, our data show that they are predominantly used in the representation of concepts based on material objects: $89 \%$ for static concepts, $11 \%$ for the representation of both static and dynamic concepts based on immaterial objects. Tables 4 and 5 further show the most and the least frequently used forms of visuals. There are a total of 146 drawings: 86 from $M$ and 60 from B. There are 50 diagrams: 2 from $M$ and 48 from B. 
There is only 1 map and it is from B. There are 11 graphs: 4 from $M$ and 7 from $B$. There are 8 flowcharts (all from B). There are 4 tables (all from B) and 5 equations (all from M).

The above statistics suggest that in $\mathrm{M}$ definitions, drawings are the most frequently encountered form of visual, while diagrams are the least frequently encountered form. In B definitions, equally drawings are the most frequently encountered form of visuals while maps are the least frequently encountered form.

Our third research question had to do with using Marsh and White's (2003) framework to determine the relationship of visual to text in definitions in the dictionaries. Table 6 first uses data from both dictionaries to illustrate Marsh \& White's broad categories, while Table 7 presents the summary findings.

Table 6. Illustrative visual-to-text relationships

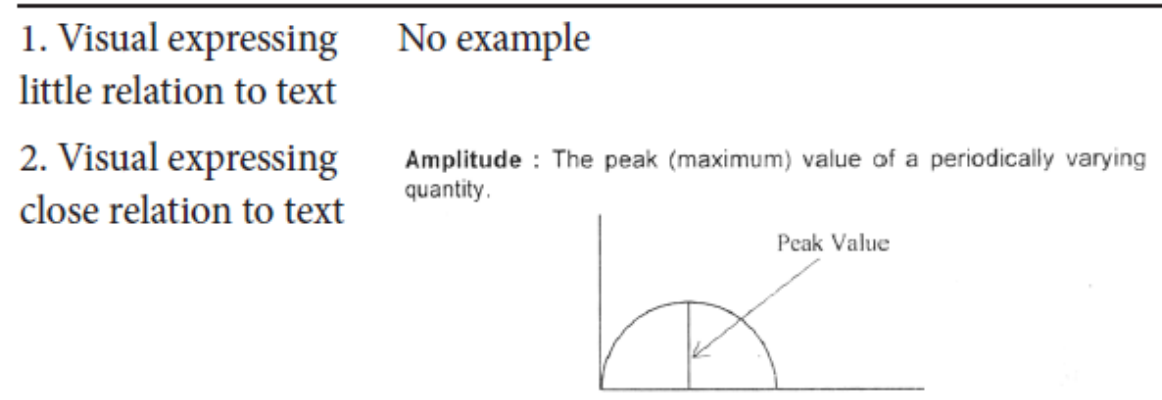

(Source: M, 21)

3. Visual expressing Organ of Corti: The sensory part of the cochlea in the inner ear, which a relation that goes responds to sound. This organ, named after Italian anatomist A. G. G. beyond text Corti (1822-88), projects into the cochlear duct and consists of two membranes that run parallel to each other: sensory hair cells, rooted in the basilar membrane, are in contact with overlying tectorial membrane (see illustration). During the transmission of sound waves the basilar membrane vibrates, causing the sensory hairs to flex against the tectorial membrane; this results in the production of impulses, which are transmitted to the brain via the auditory nerve.

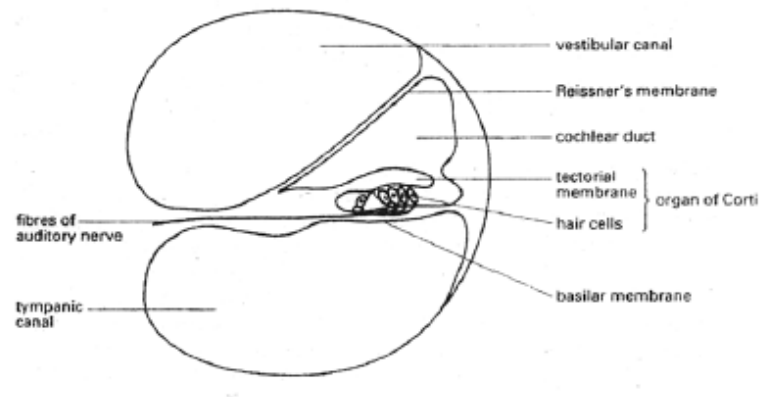

Organ of Corti (vertical settion through one turn of the cochlea

(Source: B, 423)

In Table 6, the graph illustrating the concept amplitude directly changes a varying quantity to a visual representation. The horizontal axis of the graph represents time, while the vertical axis represents a nameless quantity that changes with time. The point in time 
where this quantity reaches its maximum is what is referred to as Amplitude in M. There are two changing entities involved here: time and a nameless quantity, which can easily be represented in a graph. The fact that the visual limits itself to representing only what is said in the textual definition (the peak (maximum) value of a periodically varying quantity), and does not add any more information, justifies its assignment to the category "close relation to the text". This category appears to be served by the visual class Hupka (1989) and Kalverkämper (1993) respectively refer to as (German) "unikal" and punktuel" which selectively or narrowly focuses on the object referred to in the text, as opposed to "strukturell" (Hupka) and "systematisch" (Kalverkämper) which shows an object in its relationship to others (that are possibly not mentioned in the text). On the other hand, although the visual associated with the entry on the organ of Corti in B represents the concepts mentioned in the text, it equally indicates (at the top) the vestibular canal and Reissner's membrane, and (at the bottom) the tympanic canal in a bid to frame or organize the experience of processing textmentioned concepts. Even if such a frame is meaningless to a novice user of the dictionary, it perhaps evokes meaningful associations for users with higher levels of competence in the subject matter. The ear is divided into three sections, namely the outer ear (pinna), the middle ear and the inner ear. The organ of Corti is part of the inner ear where vibrations in response to incoming sound waves are transmitted for hearing to take place. The visual does not only perform the function of evoking meaningful associations with closely related concepts; it most importantly enables readers to picture the phenomenon that takes place in the mammalian ear. In Marsh and White's scheme, this is a function that goes beyond the textual definition. The organ of Corti would be an example of Hupka's structural class and Kalverkämper's systematic class, which appears well suited to serving the "beyond text" function.

To answer the third research question, then, Table 7 below identifies the functions of the visuals used in both $\mathrm{M}$ and $\mathrm{B}$ within the functional frame proposed by Marsh and White (2003).

Table 7 shows that in the specialized dictionary definitions studied, visuals are not used for functions with little or no relation to the text. We notice that in M, visuals tend to mainly perform functions with close relation to the text rather than functions which go beyond the textual definition: 70 of the 97 visuals perform functions with close relation to the text while the remaining 27 perform functions that go beyond the text. In $\mathrm{B}$, on the other hand, the case is quite the reverse: 87 of the 129 visuals used perform functions that go beyond the textual definition, while 42 of the visuals perform functions with close relation to the textual definition.

Table 7. Number of visuals per broad functional category

\begin{tabular}{lrcc}
\hline & M & B & TOTAL \\
\hline Little relation to text & 0 & 0 & 0 \\
Close relation to text & 70 & 42 & 112 \\
Beyond text & 27 & 87 & 114 \\
TOTAL & 97 & 129 & 126 \\
\hline
\end{tabular}


Most visuals (80) in B appear to help the learner to visualize things that cannot be directly observed. Examples include the visuals illustrating beta sheet, cellulose, and organ of Corti.

As Marsh and White's scheme in fact suggests, not all visuals assigned to one functional category "enact" that category in exactly the same manner. There are sub-types or functions under each category. In M, 34 of the 70 visual-text relationships identified as close to the text (see Table 7) perform the function translate, which involves visuals directly converting textual information to visual information, without the addition of any further details. An example can be found in the visual illustrating worm wheel in Table 1. The visual representing the above concept constitutes a toothed wheel and a helically threaded shaft (worm) that engages the toothed wheel to transmit motion. The visual presents no further details as to the kind of machine that uses such a device or the engine parts that receive the two ends of the threaded shaft. The remaining 36 visuals under the "close to the text" category enact a range of other functions.

With respect to $\mathrm{B}$, on the other hand, Table 7 shows that most visuals perform functions that go beyond the textual definition. The dominant function (attested 80 times) identified in the B data is Model, in which the visual provides a description or analogy that helps in imagining something that cannot be directly observed. One example would be the visual associated with beta sheet in Table 1. Proteins are made up of various combinations of amino acids. The structure of each protein is determined by the sequence of its constituent amino acids. The beta sheet is composed of beta strands. The visual shows the weak hydrogen bonds (dotted lines) between the beta strands N-H (amine) and the beta strands $\mathrm{C}=\mathrm{O}$ (carbonyl). The double lines between the $\mathrm{C}$ and the $\mathrm{O}$ represent double bonds between a carbon atom and an oxygen atom. This graphical representation of beta sheet helps in the visualization of the bonds connecting beta strands with each other. The remaining 7 visuals under the "beyond the text" category enact a range of other functions.

Our fourth research question was to find out whether particular forms of visuals are associated with given functions. To achieve this, we pair the forms of visuals in our data with the three functional categories of Marsh and White (2003). Table 8 presents such pairing. 
Table 8. Pairing of visual forms with visual-text relation types in B and M (separately and combined)

\begin{tabular}{|c|c|c|c|c|c|c|c|c|c|}
\hline & \multicolumn{3}{|c|}{ Little relation to the text } & \multicolumn{3}{|c|}{$\begin{array}{l}\text { Close relation to the } \\
\text { text }\end{array}$} & \multicolumn{3}{|c|}{$\begin{array}{l}\text { Relation going beyond the } \\
\text { text }\end{array}$} \\
\hline & $\mathrm{B}$ & $\mathrm{M}$ & $\begin{array}{l}\text { Com- } \\
\text { bined }\end{array}$ & B & $\mathrm{M}$ & $\begin{array}{l}\text { Com- } \\
\text { bined }\end{array}$ & B & $\mathrm{M}$ & $\begin{array}{l}\text { Com- } \\
\text { bined }\end{array}$ \\
\hline Equations & 0 & 0 & 0 & 0 & 5 & 5 & 0 & 0 & 0 \\
\hline Tables & 0 & 0 & 0 & 4 & 0 & 4 & 0 & 0 & 0 \\
\hline Graphs & 0 & 0 & 0 & 7 & 4 & 11 & 0 & 0 & 0 \\
\hline Charts & 0 & 0 & 0 & 9 & 0 & 9 & 0 & 0 & 0 \\
\hline Maps & 0 & 0 & 0 & 0 & 0 & 0 & 1 & 0 & 1 \\
\hline Diagrams & 0 & 0 & 0 & 0 & 0 & 0 & 48 & 2 & 50 \\
\hline Drawings & 0 & 0 & 0 & 22 & 61 & 83 & 38 & 25 & 63 \\
\hline
\end{tabular}

There are a number of points that Table 8 indicates. First, all the five equations used in $\mathrm{M}$ definitions perform functions with close relation to the text. All the four tables used in B perform functions with close relation to the text. All the eleven graphs used in both $\mathrm{M}$ and $\mathrm{B}$ definitions perform functions with a close relation to the text. All the fifty diagrams used in both M and B definitions perform functions that go beyond the text. Sixty-one of the eighty-six drawings used in the $\mathrm{M}$ definitions perform functions with a close relation to the text while the remaining twenty-five perform functions that go beyond the text. Conversely in B definitions, twenty-two of the sixty drawings used perform functions with a close relation to the text while thirty-eight (majority) perform functions that go beyond the textual definition. The only map in our data performs a function that goes beyond the text.

Table 8 further shows that equations, tables, graphs and charts are employed strictly for functions with a close relation to the verbal definition while diagrams are employed to perform functions that go beyond the text. Drawings are seen to perform both functions: close relation to the text and functions that go beyond the text.

\section{Discussion}

In explaining a subset of the results presented above, it is useful to consider both the nature of a specialized dictionary as well as the ontology (the nature of material) of Biology and Mechanical Engineering, at least of the material documented in both dictionaries.

Mechanical Engineers use scientific principles such as thermodynamics, mechanics and kinematics in the design, development, manufacturing and testing of tools, engines, and machines that produce, transmit and use energy. They are concerned, practically, with mechanisms and methods that convert natural energy sources to practical uses, the design of tools that other engineers use, the various types of power-using machines, machine tools, material handling systems, elevators and escalators, industrial production 
equipment, robots used in manufacturing as well as technical sales. Given this nature of Mechanical Engineering, its subject field dictionary entries are predominantly practical tools, testing methods, manufacturing processes, machines and machine parts. The visuals employed in defining disciplinary concepts most often just give a visual equivalent (typically a drawing) of a textual description of a tool, a testing method, a manufacturing process, a machine, or a part of a machine.

On the other hand, Biology is concerned with life: from the tiniest units of living organisms (cells), the profound details of every living thing, the genetic structure of organisms, reproductive systems, the deciphering of the human genetic information, the sequence of deoxyribonucleic acid (DNA) bases, to enormous creatures like elephants and the interaction between all living creatures (both those that are visible and those that are microscopic) and the environment. As such, Biology studies everything associated with plants and animals such as their origin, development, reproduction and adaptation to the environment. It is therefore not surprising that the Biology dictionary contains a substantial number of concepts of objects that are not directly observable by the human eyes (such as the nervous system, the composition of genes, blood circulation, DNA bases, photosynthesis, molecular structure, bonding, and blood composition). Such biological concepts are best represented in a codified diagrammatic way. The visuals used for defining such concepts usually do not just repeat the content of the textual definition: they help the reader to visualize the complex workings of systems beyond surface appearances. In so doing, the visuals often include concepts not found in the definitional statement in a bid to engender significant and consequential relationships.

The absence of functions with little relation to the textual definition in our data coincides, incidentally, with the absence of photographs. Photographs at times tend to communicate superficial and elementary information. To ensure the transmission of detailed information, specialized dictionaries may tend to employ diagrams and drawings which are capable of unveiling the multi-layered structures of many specialized concepts. Hupka (1989a) points to research on cognitive processing suggesting that a simple drawing may be more easily recognizable and understandable than a photograph. A Biology teacher would invariably use a drawing rather than a photograph of a mammalian heart to teach students how the heart functions. 

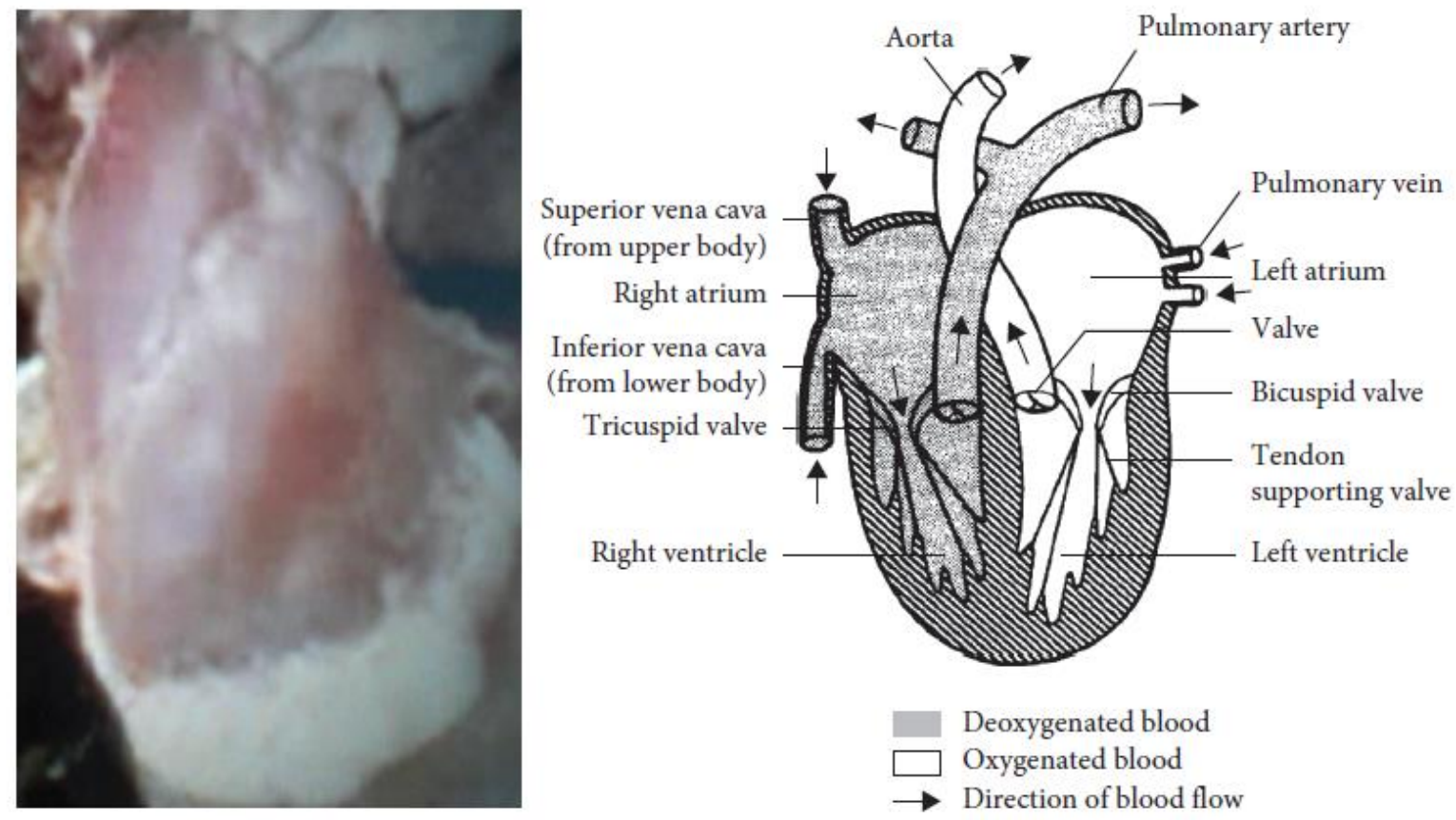

Figure 1. Level of detail in a photograph versus drawing

This is because drawings tend to reveal more details in an object than a photograph. Consider the two visual representations of the mammalian heart in Figure 1.

Some of the findings of our study have implications for definitions of visual types, the use of visuals in dictionary (in comparison to other text genres) and for further (confirmatory) research. In the only field (M) where equations are attested, they are not associated with concepts of material objects. A plausible explanation could be that equations are only associated with immaterial entities, either static or dynamic.

Another finding concerns the use of graphs. The results (Tables 4 and 5) showed that graphs are not at all used by both fields for concepts of material objects, neither static nor dynamic. In the study, it is only in the definition of immaterial objects (static or dynamic) that graphs occur.

A third finding relates to diagrams and the text-visual function they tend to be associated with. The results (Table 8) showed that all the diagrams were associated with the function "beyond text" in both B and M. The association of diagrams with this particular function of transcending the text would appear quite consistent with the very definition of a diagram as a form of visualization that "explains rather than represents".

These findings enable us to engage with aspects of Lengler and Eppler's periodic table of visualization methods. Although the definition we infer from the periodic table for a diagram (a method of visualization for mainly representing processes or stages in the attainment of an objective) does not apply to all visual terms that are morphologically classified as types of diagram in the periodic table, it can be shown to hold true for most. Now, it would be recalled from both Tables 4 and 5 of our study that with respect to material objects, diagrams are used with related static but not dynamic concepts. 
However, for concepts of immaterial objects, diagrams are used with both static and dynamic concepts (examples: dedendum on Table 4 and dihybrid cross on Table 5). Although all the diagrams in our data are used to represent material as well as immaterial objects, it is instructive to note that all these objects are not directly observable to the human eye. Examples include dedendum, and cladistics.

Combining the foregoing with the third finding presented above, our study would seem to suggest the following parametric or intensional definition of a diagram:

explanatory rather than representative, often going beyond textual definition, can be used for both static and dynamic concepts, the corresponding objects are not directly visible to the human eye.

The results of this study differ from findings associated with the analysis of other text genres, especially newspapers, literature books, textbooks, and children's books. Studies of some of these other genres, such as Darian (2001), Järvi (2002) and Dimopoulos et al. (2003) for instance, identify text-visual functions analogous to what Marsh and White (2003) refer to as little or no relation to the text. In our study, however, no such functions were identified. This particular function, according to Marsh and White (2003), manifests as, among others, decorate (make the text more attractive without aiming to produce any real effects on the reader's understanding or memory), elicit emotion (encourage emotional response from the reader through a display of content or style that is especially arresting or disturbing), engage (hold the attention of the reader), and motivate (encourage some response from the reader). The absence of this function in our data might be attributed to the fact that specialized dictionaries, unlike newspapers and literature books, are consulted when a need arises to bridge a particular knowledge gap often for instrumental purposes. They are not typically read from the beginning to the end like some other books. As such, specialized dictionary entries are presented without any adornment, or mood-changing strategies.

\section{Conclusion}

The main impetus for undertaking this study was that even though the fortunes of visuals in linguistic theorization have changed for the better in recent times, much of the supporting work is based on scientific writing, newspapers and children's books. Dictionaries, both general and specialized, have not been given the attention they deserve although they too often contain visual material. This study has shown that findings from studies of other text genres are not necessarily transferable to dictionaries.

From the standpoint of developing terminology theory further, this study has shown the opportunities that exist in researching:

- The types of visuals employed in specialized dictionaries;

- The relationship between types of definiendum and choice of visual type;

- The relationship between the text of definitions and visuals;

- The relationship between visual type and function. 
Further research might seek to verify the findings of this study. Clearly, a major challenge for studies in this area is, paradoxically, the terminology. A systematic dictionary of visual types that is the outcome of standardization initiatives is certainly desirable.

\section{Notes}

1. A machine used for forcing an arbor or a mandrel into drilled or bored parts preparatory to turning or grinding.

2. The radial distance between two concentric circles on a gear, one being that whose radius extends to the top of the gear tooth (addendum circle) and the other being that which will roll without slipping on a circle on a mating gear (pitch line).

3. It is defined as the rate of change of velocity with respect to time.

4. The organ of sight. The most primitive eyes are the eyespots of some unicellular organisms. More advanced are the ocelli and compound eyes of arthropods (e.g. insects).

5. A controversial method of classification in which animals and plants are placed into taxonomic groups called clades strictly according to their evolutionary relationships...

6. A form of population growth in which the rate of growth is related to the number of individuals present. Increase is low when numbers are low but rises sharply when numbers increase. 


\section{References}

Antia, B. E. 2000. Terminology and Language Planning: An Alternative Framework of Practice and Discourse. Amsterdam: John Benjamins Publishing Company.

Antia, B. E. 2002. "Concepts as Predications, Terminologies as Multimedial Texts." Terminology Science \& Research 13 (1-2): 27-31.

Antia, B. E. 2005. "Definitions in Terminology." A presentation at the Workshop on International Training on the Basic Principles of Terminology Management, South-Africa, September 26-30, 2005. Accessed June 20, 2012. www.termnet.org/enlish/TermTrain presentation.php.

Arora, R. S. 2007. Academic's Dictionary of Mechanical Engineering. New Delhi: Academic Publishers.

Barnbrook, G. 2003. "The Language of Definition." Unpublished PhD dissertation, University of Birmingham.

Blachowicz, C. L. Z., P. J. Fisher, and S. Watts-Taffe. 2005. Integrated Vocabulary Instruction: Meeting the Needs of Diverse Learners in Grades K-5. Naperville: Learning Point Associates.

Bowker, L. 1997. "Multidimensional Classification of Concepts and Terms." In Handbook for Terminology Management, ed. by S. E. Wright and G. Budin, Vol. 1, 133-143. Amsterdam: John Benjamins Publishing Company.

Chomsky, N. 1968. Language and Mind. New York: Harcourt, Brace \& World. ।

Dahlberg, I. 1995. "Conceptual Structures \& Systematization.” International Forum on Information \& Documentation 20 (3): 9-24.

Darian, S. 2001. "More than Meets the Eye: The Role of Visuals in Science Textbooks." LSP \& Professional Communication 1 (1): 10-36.

de Bessé, B. 1997. "Terminological Definitions." In Handbook for Terminology Management, ed. By S. E. Wright and G. Budin, Vol. 1, 63-74. Amsterdam: John Benjamins Publishing Company.

Dimopoulos, K., V. Koulaidis, and S. Sklaveniti. 2003. "Towards an Analysis of Visual Images in School Science Textbooks and Press Articles about Science and Technology." Research in Science Education 33: 189-216.

Doblin, J. 1980. "A structure for Nontextual Communications." In Processing a Visible Language, ed. by P.A. Knowles and H. Bohma, 89-111. New York: Plenum.

Eck, E., and E. Meyer. 1995. "Bringing Aristotle into the 2oth Century. Computer-aided Definition Construction in a Terminological Knowledge Base." In Standardizing and Harmonizing Terminology: Theory and Practice, ed. by S. E. Wright and R. A Strehlow, 83-100. Philadelphia: ASTM.

Faber, P., P. Leon-Arauz, J. A. Prieto-Velasco, and A. Reimerink. 2007. "Linking Images and Words: The Description of Specialized Concepts." International Journal of Lexicography 20 (1): 39-65.

Galinski, C., and H. Picht. 1997. "Graphic and Other semiotic Forms of Knowledge Representation in Terminology Management." In Handbook of Terminology Management, ed. by S. E.Wright, and G. Budin, Vol. 1, 42-61. Amsterdam: John Benjamins Publishing Company.

HarperCollins Publishers. 2006. Collins Cobuild Advanced Learner's English Dictionary. Glasgow: HarperCollins Publishers.

Hupka, W. 1989a. "Die Bebilderung und sonstige Formen der Veranschaulichung im einsprachigen Wörterbuch.” In Wörterbücher. Dictionaries. Dictionnaires. Ein 
internationals Handbuch zur Lexikographie, ed. by F. J. Hausmann, O. Reichmann, H. E. Wiegand, and L. Zgusta, Vol. 1, 704-726. Berlin, New York: Walter de Gruyter.

Hupka, W. 1989b. "Das enzyklopädische Wörterbuch.” In Wörterbücher. Dictionaries.

Dictionnaires. Ein internationales Handbuch zur Lexikographie, ed. by F. J. Hausmann, O. Reichmann, H. E. Wiegand, and L. Zgusta, Vol. 1, 988-999. Berlin, New York: Walter de Gruyter.

Hupka, W. 1999. "Illustrationen im Fachwörterbuch." In Fachsprachen. Languages for Special Purposes. Ein internationales Handbuch zur Fachsprachenforschung und 